\title{
LKB1 and AMPK and the cancer-metabolism link - ten years after
}

\author{
D Grahame Hardie* and Dario R Alessi
}

\begin{abstract}
The identification of a complex containing the tumor suppressor LKB1 as the critical upstream kinase required for the activation of AMP-activated protein kinase (AMPK) by metabolic stress was reported in an article in Journal of Biology in 2003. This finding represented the first clear link between AMPK and cancer. Here we briefly discuss how this discovery came about, and describe some of the insights, especially into the role of AMPK in cancer, that have followed from it.
\end{abstract}

In September 2003, our groups published a joint paper [1] in Journal of Biology (now BMC Biology) that identified the long-sought and elusive upstream kinase acting on AMP-activated protein kinase (AMPK) as a complex containing LKB1, a known tumor suppressor. Similar findings were reported at about the same time by David Carling and Marian Carlson [2] and by Reuben Shaw and Lew Cantley [3]; at the time of writing these three papers have received between them a total of over 2,000 citations. These findings provided a direct link between a protein kinase, AMPK, which at the time was mainly associated with regulation of metabolism, and another protein kinase, LKB1, which was known from genetic studies to be a tumor suppressor. While the idea that cancer is in part a metabolic disorder (first suggested by Warburg in the 1920s [4]) is well recognized today [5], this was not the case in 2003, and our paper perhaps contributed towards its renaissance. The aim of this short review is to recall how we made the original finding, and to discuss some of the directions that these findings have taken the field in the ensuing ten years.

*Correspondence: d.g.hardie@dundee.ac.uk

'Division of Cell Signalling and Immunology, College of Life Sciences, University of Dundee, Dundee, DD1 5EH, Scotland, UK

Full list of author information is available at the end of the article

\section{AMPK as an energy sensor and metabolic switch}

AMPK was discovered as a protein kinase activity that phosphorylated and inactivated two key enzymes of fatty acid and sterol biosynthesis: acetyl-CoA carboxylase (ACC) and 3-hydroxy-3-methylglutaryl-CoA reductase (HMGR). The ACC kinase activity was reported to be activated by 5'-AMP [6], and the HMGR kinase activity by reversible phosphorylation [7], but for many years the two activities were thought to be due to distinct enzymes. However, in 1987 the DGH laboratory showed that both were functions of a single protein kinase [8], which we renamed AMPK after its allosteric activator, 5'-AMP [9]. It was subsequently found that AMPK regulated not only lipid biosynthesis, but also many other metabolic pathways, both by direct phosphorylation of metabolic enzymes, and through longer-term effects mediated by phosphorylation of transcription factors and coactivators. In general, AMPK switches off anabolic pathways that consume ATP and NADPH, while switching on catabolic pathways that generate ATP (Figure 1). Findings that AMPK is activated in skeletal muscle during exercise [10] and that it increases muscle glucose uptake and fatty acid oxidation [11] led to the suggestion that AMPK-activating drugs might be useful for treating type 2 diabetes [12]. Indeed, it turned out that AMPK is activated by metformin, a drug that had at that time been used to treat type 2 diabetes for over 40 years, [13], and by phenformin [1], a closely related drug that had been withdrawn for treatment of diabetes due to side effects of lactic acidosis.

Metformin and phenformin are biguanides that inhibit mitochondrial function and so deplete ATP by inhibiting its production [14]. AMPK is activated by any metabolic stress that depletes ATP, either by inhibiting its production (as do hypoxia, glucose deprivation, and treatment with biguanides) or by accelerating its consumption (as does muscle contraction [10]). By switching off anabolism and other ATP-consuming processes and switching on alternative ATP-producing catabolic pathways, AMPK acts to restore cellular energy homeostasis. When ATP is consumed, both ADP and

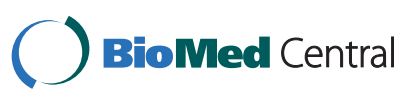

(c) 2013 Hardie and Alessi; licensee BioMed Central Ltd. This is an Open Access article distributed under the terms of the Creative Commons Attribution License (http://creativecommons.org/licenses/by/2.0), which permits unrestricted use, distribution, and reproduction in any medium, provided the original work is properly cited. 


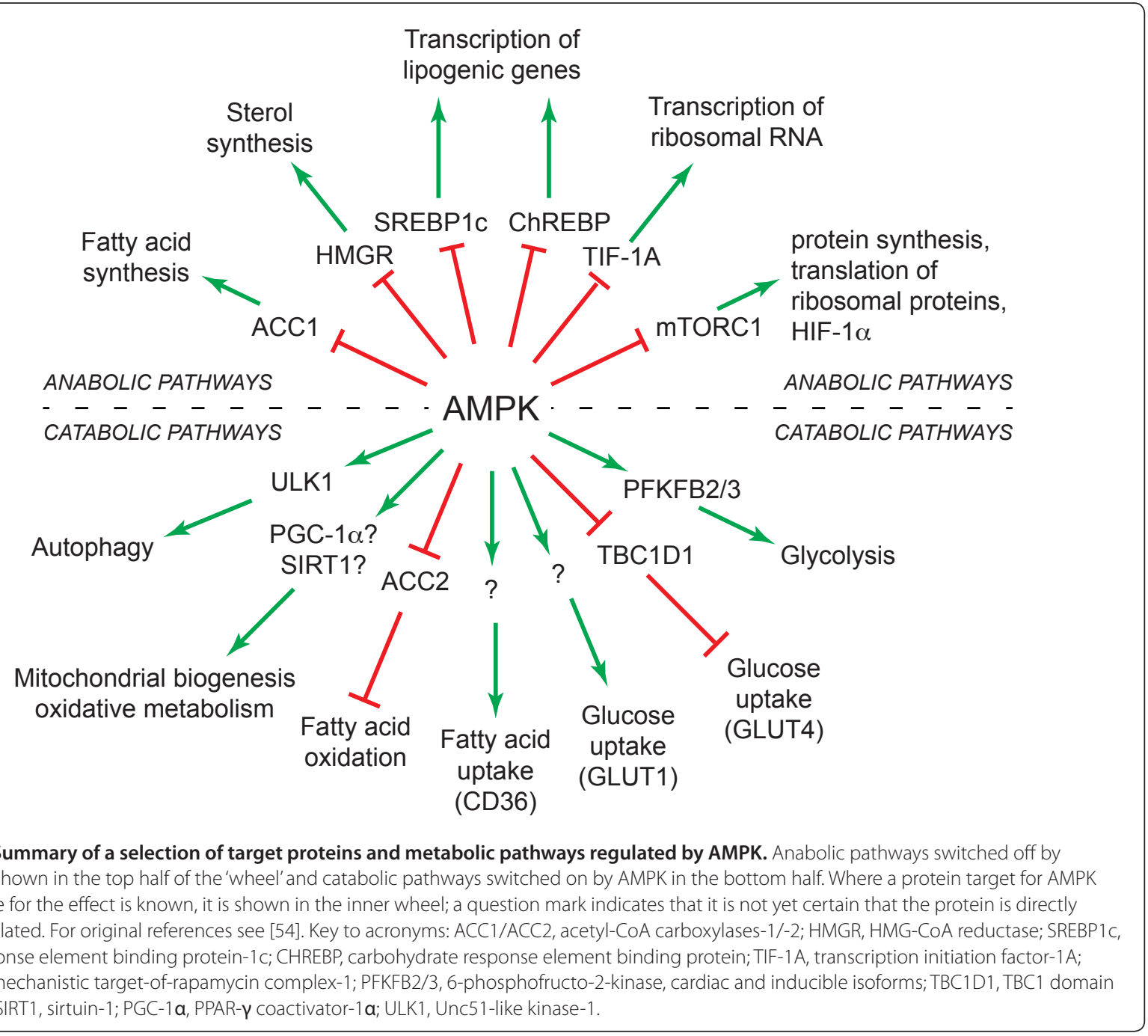

AMP increase, and it has recently become clear that both of the latter are activators of AMPK. ATP competes with AMP and ADP for binding to regulatory sites on the enzyme, thus preventing activation; activation of AMPK therefore depends on the ratios of ATP:ADP and AMP:ATP, and in this way the enzyme acts as a sensor of the metabolic state of the cell.

AMPK has two regulatory subunits, $\beta$ and $\gamma$, along with its catalytic a subunit (Figure 2). Like most kinases, it is activated by phosphorylation of a residue within the activation loop of the kinase domain (Thr172). The $\gamma$ subunit contains four tandem sequence repeats known as CBS repeats, which are arranged in a pseudosymmetrical manner to yield four potential adenine nucleotide-binding clefts. One of these (site 2) appears always to be unoccupied, one (site 4) appears to have permanently bound AMP, while the remaining two (1 and 3) bind AMP, ADP or ATP in competition $[15,16]$. In an unstressed cell where ATP:ADP ratios are high, sites 1 and 3 are probably largely occupied by ATP, but when a cell undergoes metabolic stress the concentrations of ADP and AMP increase relative to ATP, and they will progressively replace ATP at sites 1 and 3. Thr172 appears to be phosphorylated constantly by the upstream kinase, but under unstressed conditions it is immediately dephosphorylated, so that the net phosphorylation state remains close to zero. However, binding of ADP and/or AMP to the $\gamma$ subunit both promotes phosphorylation and inhibits dephosphorylation of Thr172, causing a sensitive switch to the active, phosphorylated form. In addition, binding of AMP (but not ADP) causes a further allosteric activation of the phosphorylated kinase; this additional mechanism may further amplify the response in a severely stressed cell in which AMP levels are high.

This leaves open the question of the activating kinase that phosphorylates Thr172. It had been known since studies of 'HMGR kinase' in 1978 [7] that AMPK was activated by a distinct upstream kinase, but its identity had remained enigmatic. 


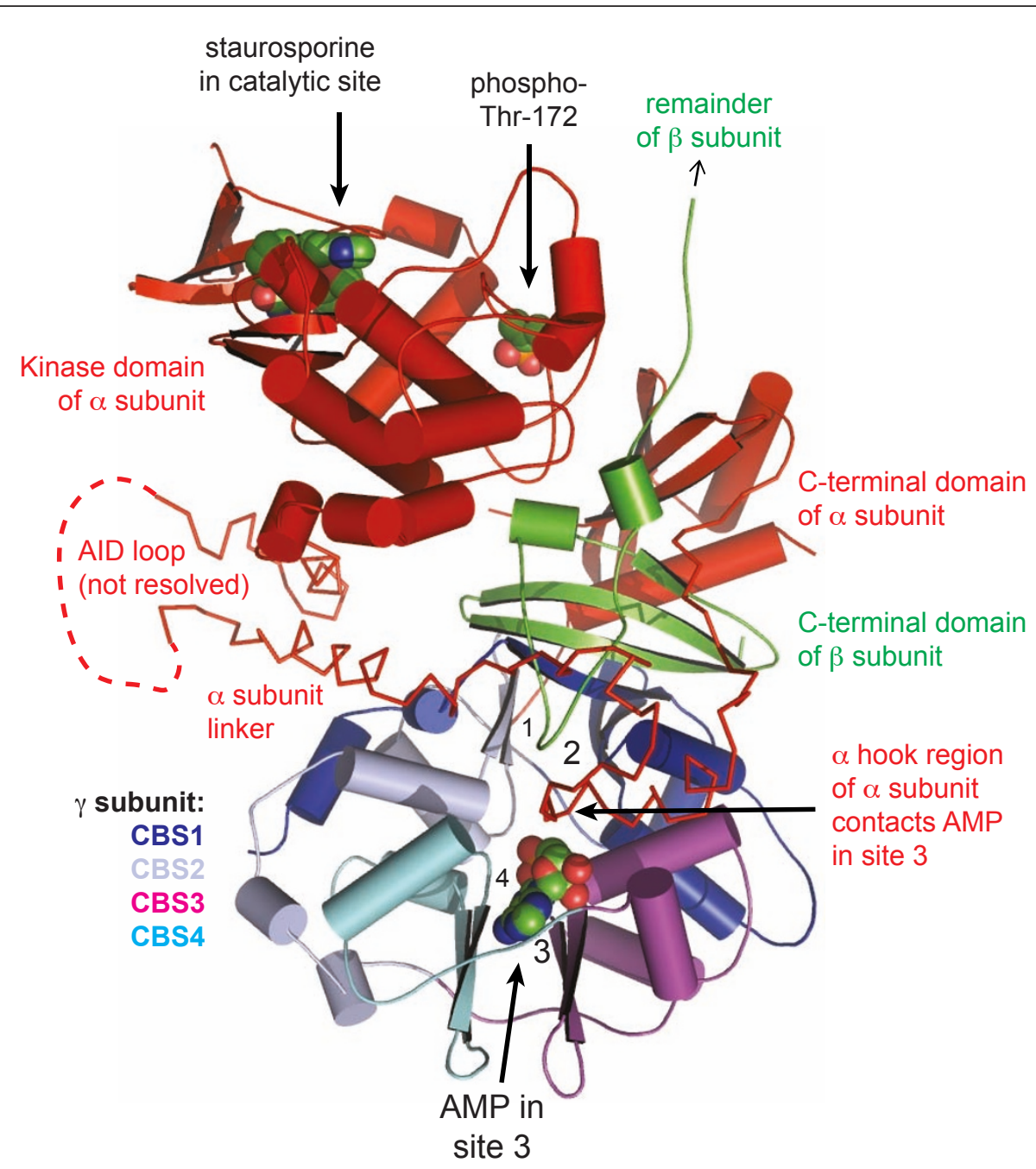

Figure 2. Structure graphic of AMPK. The a subunit is in red, the $\beta$ subunit in green, and the four CBS motifs of the $\gamma$ subunit in various shades of blue, magenta and cyan. For this structure, an AMPK complex phosphorylated on Thr172, lacking most of the $\beta$ subunit and also a flexible loop from the a subunit, was crystallized in the presence of AMP and the kinase inhibitor staurosporine. For clarity, only the AMP in site 3 is shown, but the approximate location of binding clefts 1,2 and 4 are also shown; in this view, sites 1 and 4 are at the back of the $\gamma$ subunit and sites 2 and 3 at the front. The carboxy-terminal domain of the $\beta$ subunit forms the core of the complex, bridging the carboxy-terminal domain of the a subunit and the $\gamma$ subunit. Note the extended a subunit linker peptide between the kinase domain and carboxy-terminal domain, with its 'a hook' region contacting AMP in site 3. AID: a subunit autoinhibitory domain (this domain is believed to hold the catalytic domain in an inactive conformation in the absence of the regulatory domains). Drawn using MacPyMOL with Protein Database Entry 2 Y94 [15].

\section{Discovery of the link between LKB1 and AMPK}

Although by 1996 the DGH laboratory had partially purified an upstream kinase from rat liver that phosphorylated Thr172 [17], we had been unable to identify it. The breakthrough came when we switched to the yeast Saccharomyces cerevisiae, which contains a protein kinase (the SNF1 complex) that is a clear orthologue of AMPK $[18,19]$. The S. cerevisiae genome sequence had just been completed, and we screened a yeast kinome expression library for kinases that activated mammalian AMPK. This yielded Elm1 as a single hit, although, frustratingly, knocking out the ELM1 gene did not produce the same phenotype as knocking out SNF1. However, Martin Schmidt's group had just shown that a closely related kinase, Pak1 (now called Sak1) could also phosphorylate and activate the SNF1 complex [20], and working with him we observed the expected phenotype by making a triple knockout not only of Elm1 and Sak1 but also of Tos3, a third closely related kinase [21]. The Carling and Carlson groups simultaneously identified the same three upstream kinases [22].

Although there were no clear orthologues of Elm1, Sak1 or Tos3 in mammals, the human kinase with closest sequence similarity (at least within the kinase domain) 
was LKB1 (liver kinase B1), which had been identified five years earlier as a tumor suppressor mutated in an inherited cancer susceptibility called Peutz-Jeghers syndrome [23,24]. The DRA laboratory had started to study LKB1 at that time, and had made the key observation that the enzyme was only active as a complex with two accessory subunits called STRAD and MO25 $[25,26]$. Working together, we were quickly able to demonstrate (using antibodies that DRA had generated) that the upstream kinase that the DGH group had been trying to purify from rat liver was indeed an LKB1STRAD-MO25 complex. We also showed that activation of AMPK by metabolic stress in LKB1-null cells was defective, but could be rescued by re-expression of LKB1. These findings formed the basis of our paper in Journal of Biology [1]. The LKB1 complex was not itself regulated by AMP, with the effects of AMP or ADP on Thr172 phosphorylation being due instead, as described above, to binding of the nucleotides to the substrate, AMPK, causing conformational changes that promote phosphorylation and inhibit dephosphorylation [15,2729] (Figure 3).

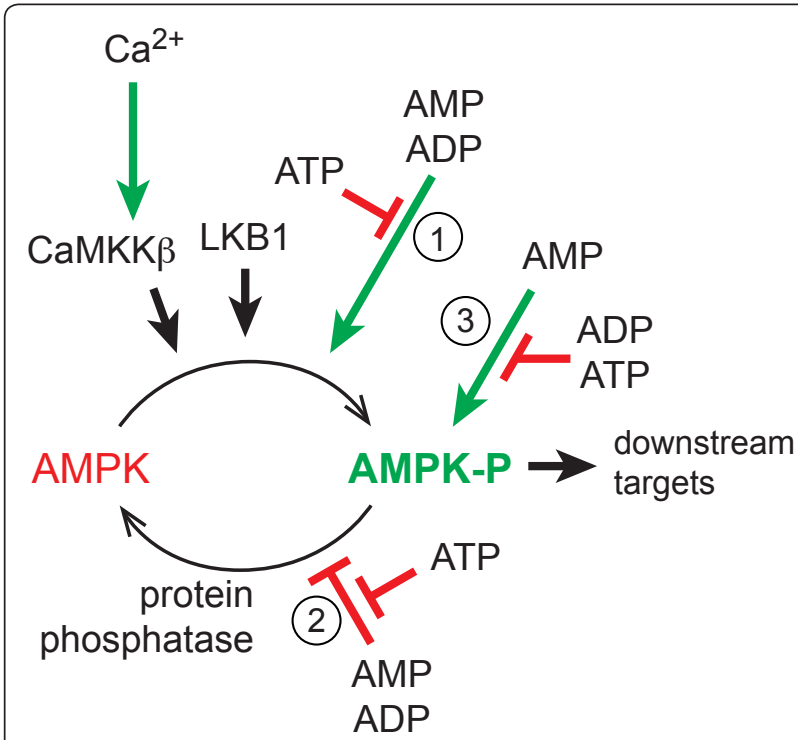

Figure 3. Regulation of AMPK. AMPK can be activated by increases in cellular AMP:ATP or ADP:ATP ratio, or $\mathrm{Ca}^{2+}$ concentration. AMPK is activated $>100$-fold on conversion from a dephosphorylated form (AMPK) to a form phosphorylated at Thr172 (AMPK-P) catalyzed by at least two upstream kinases: LKB1, which appears to be constitutively active, and CaMKK $\beta$, which is only active when intracellular $\mathrm{Ca}^{2+}$ increases. Increases in AMP or ADP activate AMPK by three mechanisms: (1) binding of AMP or ADP to AMPK, causing a conformational change that promotes phosphorylation by upstream kinases (usually this will be LKB1, unless $\left[\mathrm{Ca}^{2+}\right]$ is elevated); (2) binding of AMP or ADP, causing a conformational change that inhibits dephosphorylation by protein phosphatases; (3) binding of AMP (and not ADP), causing allosteric activation of AMPK-P. All three effects are antagonized by ATP, allowing AMPK to act as an energy sensor.

\section{The immediate aftermath (1): more kinases downstream of LKB1}

While it was clear at that time that most kinases require phosphorylation in the activation loop to become active, it was also self-evident that there could not be a specific upstream kinase for every downstream kinase. The DRA group had previously identified PDK1 as the upstream kinase for $\mathrm{PKB} / \mathrm{Akt}[30]$, and shown that it was also upstream of several other members of the AGC kinase family, introducing the concept of 'master upstream kinases' [31]. The two catalytic subunit isoforms of AMPK ( $a 1$ and $a 2$ ) lie on a small sub-branch of the CaMK kinase family [32] that also contains 12 other kinases now referred to as the AMPK-related kinases or ARKs. Since the sequence around the site equivalent to Thr172 is highly conserved between AMPK and the ARKs, it seemed possible that LKB1 was a master kinase upstream of the whole subfamily, and this was soon shown to be the case [33,34] (Figure 4). Indeed, LKB1 activates all 12 ARKs by phosphorylating the residue equivalent to Thr172, and their activity is greatly diminished in LKB1-deficient cells.

Although the roles of the ARKs are poorly understood by comparison with those of AMPK, initial studies suggest that they play critical roles in regulating aspects of cell polarity (MARK, BRSK/SAD), cell proliferation (NUAKs) and CREB-regulated gene transcription (SIKs). The catalytic subunits of the ARKs do not interact with the $Y$ subunits that provide the AMP/ADP sensing function of the AMPK complex [35], so they are not regulated by energy stress like AMPK, and indeed it is not yet understood how their activity and phosphorylation is regulated at the molecular level. As discussed below, however, their existence complicates the interpretation of the metabolic and tumor suppressor effect of LKB1, in particular in the case of the NUAKs,

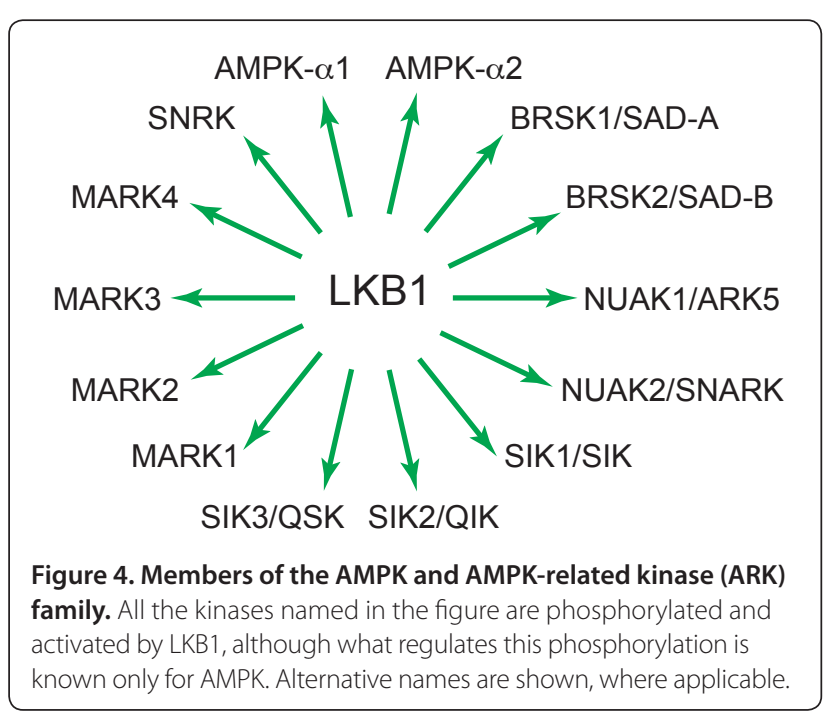


which appear to be involved in regulation of cell proliferation, and the SIKs, involved in the regulation of gluconeogenesis.

\section{The immediate aftermath (2): more kinases upstream of AMPK}

Our 2003 paper [1] showed that although genetic loss of LKB1 in mammalian cells greatly reduces phosphorylation of AMPK on Thr172, it does not eliminate it entirely, suggesting that other kinases must also phosphorylate the site. The DGH group had reported in 1995 that calmodulin-dependent kinase kinases (CaMKKs) could activate AMPK [27], although it was not clear at the time that this was physiologically relevant. However, DGH and others soon reported that CaMKKs (especially the CaMKK $\beta$ isoform) did indeed provide an alternative $\mathrm{Ca}^{2+}$-stimulated pathway by which AMPK could be activated in intact cells in the absence of LKB1 [36-38]. This pathway accounts for AMPK activation in neurones exposed to membrane depolarization [36], in $\mathrm{T}$ cells activated via the antigen receptor [39], and in cells treated with ligands for $G$ protein-coupled receptors that trigger intracellular release of inositol trisphosphate and hence $\mathrm{Ca}^{2+}$. The latter include endothelial cells treated with thrombin [40], and hypothalamic neurones involved in appetite control treated with the 'hunger hormone' ghrelin $[41,42]$. Interestingly, despite the very close sequence similarities within the activation loops of AMPK and the ARKs, none of the ARKs appear to be phosphorylated and activated by CaMKK $\beta$ [43].

\section{New findings arising from genetic ablation of LKB1}

Null mutations of either LKB1 or AMPK are embryonic lethal in mice, which means that conditional knockouts are necessary to study their function in vivo. This is, however, complicated in the case of AMPK by the existence of two or three functionally redundant isoforms of each of the three subunits, so that genes encoding all isoforms of one subunit must be knocked out to produce a phenotype. The identification of LKB1 as the upstream kinase activating AMPK simplified the investigation of AMPK function in vivo, because LKB1 is encoded by a single gene. It allowed the demonstration, for example, that mice with a muscle-specific knockout of LKB1, in which AMPK was no longer activated by contraction, failed to display the normal increase in muscle glucose uptake in response to contraction [44]. The convenience of having to knock out only a single gene is counterbalanced, however, by the status of LKB1 as a master upstream kinase that also acts upstream of the ARKs: thus, a phenotype caused by a tissue-specific LKB1 knockout cannot simply be ascribed to loss of AMPK activation without additional evidence. In the case of the muscle-specific LKB1 knockout, such evidence has been provided by a later study showing that skeletal muscle in which both AMPK- $\beta$ subunits are knocked out to ablate AMPK activity have a rather similar phenotype [45]. By contrast, distinct effects of knocking out LKB1 and AMPK can be seen in the case of the liver, in which loss of LKB1 causes marked hyperglycemia, whereas mice with liver-specific loss of both AMPK catalytic subunits are normoglycemic. The more severe phenotype caused by ablation of LKB1 rather than AMPK in the liver may be due to reduced activity of SIK1, which as mentioned earlier regulates expression of gluconeogenic genes [46].

\section{The role of AMPK in cancer}

As pointed out in an accompanying mini-review at the time [47], perhaps the biggest impact of our paper and the others linking LKB1 and AMPK [1-3] came from the link they established between a tumor suppressor (LKB1) with roles in cancer, and a protein kinase (AMPK) that had previously been regarded as a regulator of metabolism, with clinical implications in diabetes but not in cancer. While such a link had been suggested previously by pioneering work from the Esumi laboratory $[48,49]$, the three simultaneous reports that LKB1 acted upstream of AMPK brought it into sharper focus. A key question was whether the tumor suppressor functions of LKB1 were mediated by AMPK, or by one or more of the ARKs, or both. This has still not been completely resolved, although there are good reasons for expecting that AMPK may mediate some of the tumor suppressor functions of LKB1. Indeed, a tumor suppressor function for AMPK is supported by a recent paper reporting that a whole-body knockout of AMPK- $\alpha 1$, which is the only catalytic subunit expressed in B cells, accelerates the development of lymphomas in transgenic mice overexpressing c-Myc in the B cells [50]. More generally, actions of AMPK that suggest it may be responsible for some of the tumor suppressor functions of LKB1 are as follows.

First, AMPK activation causes a cell cycle arrest associated with stabilization of p53 and the cyclindependent kinase inhibitors p21 $1^{\text {WAF1 }}$ and p27 CIP1 $[49,51,52]$. Second, AMPK activation inhibits the synthesis of most cellular macromolecules, including fatty acids, triglycerides, cholesterol, glycogen, ribosomal RNA and proteins [53,54], thus inhibiting cell growth. It is particularly significant in this respect that AMPK inhibits the mechanistic target-of-rapamycin complex-1 (mTORC1) by phosphorylating its upstream regulator TSC2 [55] and its regulatory subunit Raptor [56] and thus inhibits translation of many proteins required for rapid cell growth, including hypoxia-inducible factor-1a (HIF-1a). This latter effect contributes to the third 
potential tumor suppressor action of the enzyme - the 'anti-Warburg' effect. The Warburg effect is the switch away from oxidative metabolism and towards rapid glucose uptake, glycolysis and lactate output that is characteristic of most tumor cells [5]. Although AMPK activation can acutely increase glucose uptake [57] and glycolysis in certain cells $[58,59]$, in the longer term it promotes the more energy-efficient oxidative metabolism, by up-regulating mitochondrial biogenesis [60] and expression of oxidative enzymes [61], while down-regulating the glycolytic pathway by inhibiting mTORC1. Inhibition of mTORC1 decreases translation of HIF-1 $\alpha$ [62], a transcription factor that drives expression of enzymes and transporters required for the Warburg effect, including most glycolytic enzymes as well as the transporters GLUT1 and MCT4, which are required for glucose uptake and lactate output, respectively. Consistent with the idea that AMPK exerts an 'anti-Warburg' effect, expression of HIF- $1 \alpha$ and downstream glycolytic genes are up-regulated in LKB1null or AMPK- $\alpha 1-\alpha 2$ double null mouse embryo fibroblasts [63]. The Warburg effect is also enhanced in the lymphoma cells mentioned earlier, derived by c-Myc over-expression in B cells when AMPK was knocked out in vivo, as well as in lung and colon cancer cells in culture when AMPK is knocked down in vitro [50].

If the LKB1-AMPK pathway does indeed act as a tumor suppressor that normally restrains growth and proliferation of cancer cells as well as the associated metabolic changes, one would expect such cells to be under selective pressure to down-regulate the pathway. One obvious mechanism by which this happens is genetic loss of LKB1 due to somatic mutations which, as shown in our 2003 paper [1], leads to failure of AMPK activation following metabolic stresses that increase AMP and ADP (loss of LKB1 would, of course, down-regulate the ARKs as well as AMPK). Such mutations are now estimated to occur in approximately $30 \%$ of non-small cell lung cancers $[64,65]$, approximately $20 \%$ of cervical cancers [66], and approximately $10 \%$ of cutaneous melanomas [67]. There are also other mechanisms by which the pathway can be down-regulated in cancer, through direct effects on AMPK rather than as downstream consequences of LBK1 inactivation. Thus, expression of the AMPK- $\alpha 2$ subunits is reduced in some cases of hepatocellular carcinoma, and this is associated with enhanced tumor cell growth in mouse xenografts, and poorer patient prognosis [68], while in melanoma cells that carry the V600E mutation in B-Raf, LKB1 appears to be phosphorylated at carboxy-terminal sites, and this is associated with reduced AMPK activation [69].

A further potential mechanism of AMPK downregulation that may contribute to tumorigenesis depends on an inhibitory effect of phosphorylation at Ser485 by
Akt, which has been reported to prevent the activating phosphorylation at Thr172 [70]. This might occur in tumors in which Akt is hyper-activated due to loss-offunction mutations in the lipid phosphatase PTEN, or activating mutations in phosphoinositide-3-kinase (PI3K) [71]. Although this mechanism has not yet been studied in the context of cancer, it has been shown to operate in human hepatoma cells infected with hepatitis $C$ virus (HCV), in which Akt is activated due to interactions between PI3K and one of the virus-encoded nonstructural proteins, NS5A [72]. This causes a marked phosphorylation of Ser485 on AMPK- $\alpha 1$ and reduced Thr172 phosphorylation. Intriguingly, expression of an S485A AMPK- $\alpha 1$ mutant in the cells reduces expression of viral protein, suggesting that phosphorylation of AMPK at Ser485 is required for efficient viral replication [73]. Up to $80 \%$ of individuals infected with HCV develop a chronic infection, which greatly increases their risk of fatty liver disease and hepatocellular carcinoma [72]. Since activation of fatty acid oxidation and inhibition of fatty acid synthesis are two of the classical effects of AMPK [11], while AMPK can also act as a tumor suppressor, down-regulation of AMPK by HCV may help to explain the increased risk of both fatty liver disease and liver cancer.

\section{AMPK, metformin, and the prevention or treatment of cancer}

If the LKB1-AMPK pathway is indeed a tumorsuppressing pathway, then AMPK-activating drugs might be expected to provide protection against the development of cancer. Indeed, our 2003 paper [1], taken together with the earlier observations that metformin activates AMPK [13], led directly to an investigation in which it was found that type 2 diabetics treated with the AMPK-activating drug metformin had a significantly reduced incidence of all forms of cancer [74]. This has been reproduced in several subsequent studies of different diabetic populations, with a meta-analysis indicating an overall summary risk reduction of $30 \%$, with specific risk reductions being found for colon and liver cancers [75]. It should be noted that these studies merely report associations between cancer incidence in diabetics treated with metformin compared with those on other medications (typically sulphonylureas or insulin), and do not prove a causal link. They have also been criticized on the basis that they may be subject to time-related biases [76]. However, there are, as we have seen, other reasons for supposing that activation of AMPK may suppress tumorigenesis, and in this light there are at least three mechanisms that might explain its protective effects (Figure 5). The first mechanism (Figure 5a) involves the indirect action of metformin, through effects at sites other than the tumors themselves 


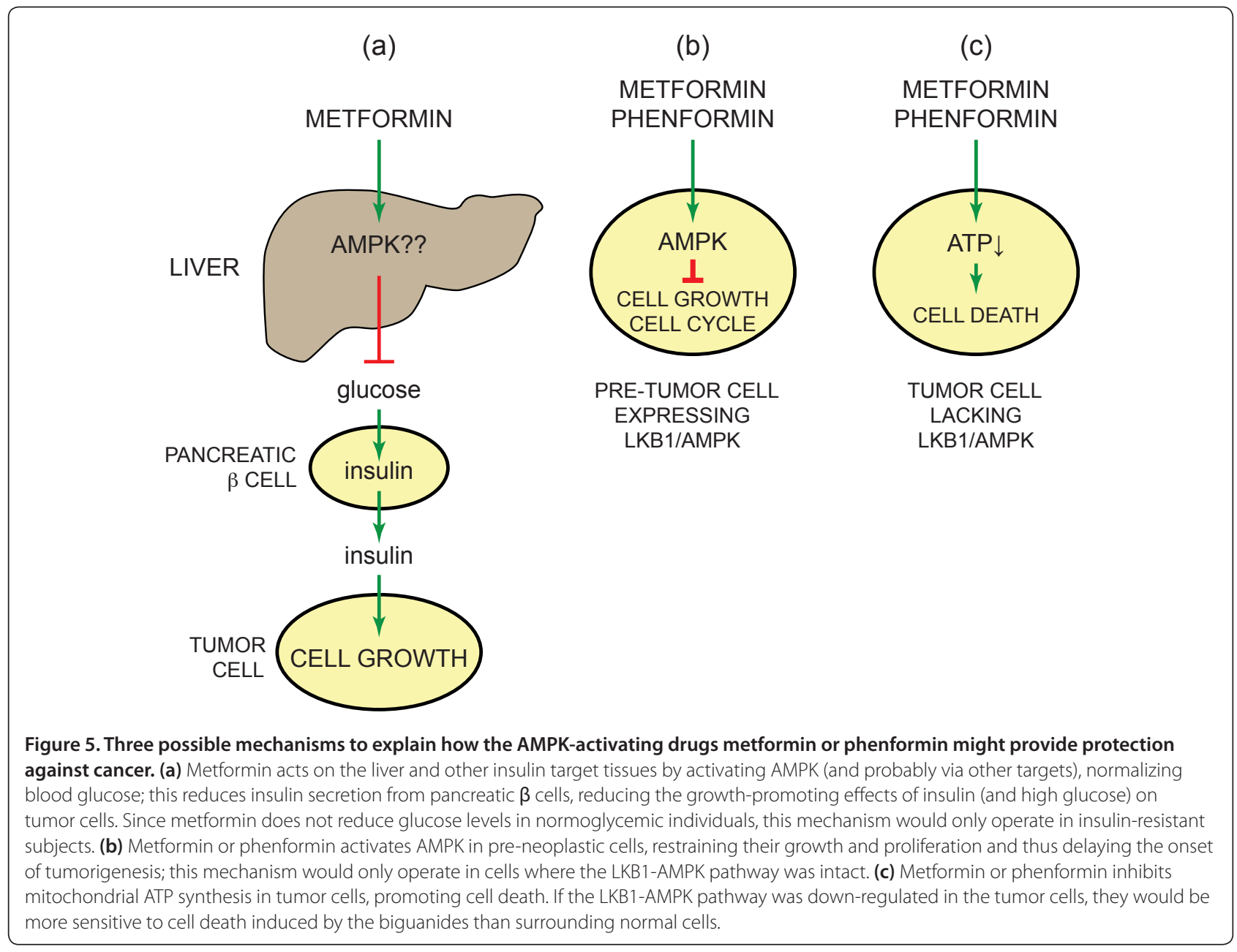

(especially the liver), while the other two (Figure 5b,c) involve direct effects of metformin on the pre-tumor or tumor cells. It is worth pointing out that these mechanisms are not mutually exclusive and all could contribute to an overall effect, although the second two mechanisms could not co-exist in a single tumor cell.

The first of the possible mechanisms (Figure 5a) derives from the observation that cancer incidence is increased in type 2 diabetics, and the contribution of AMPK in this case is not yet clear. In type 2 diabetes, reduced insulin sensitivity of insulin target tissues causes a compensatory increase in the secretion of insulin. Insulin is of course a growth factor, and there is a positive association between plasma levels of insulin and cancer [77], suggesting that elevated insulin (and perhaps also glucose) could be the cause of increased cancer in type 2 diabetics. In this case, metformin could reduce cancer incidence by enhancing the insulin sensitivity of insulin target tissues, causing normalization of blood glucose and reducing hypersecretion of insulin from pancreatic $\beta$ cells. By contrast, other treatments, including sulphonylureas (which enhance insulin release from $\beta$ cells), and injection of insulin, will tend to increase plasma insulin. Some support for this mechanism comes from studying growth of colon carcinoma (MC38) cells as mouse xenografts. When the mice are fed a high-fat diet to render them insulin-resistant and thus increase plasma insulin, growth of the implanted tumors is enhanced; metformin treatment reverses both the increase in plasma insulin and the tumor growth rate [78]. In such xenograft studies, the tumor cells of course already exist, and insulin is merely affecting their growth rate.

\section{Direct effects of biguanides in tumor cells and the emergence of a paradox}

Other studies suggest that metformin might delay the initial development of tumors by direct actions on the tumor cells themselves, even in animals that are not insulin-resistant. For example, in mice that are tumorprone due to heterozygous loss of PTEN combined with reduced expression of LKB1, development of tumors (mostly lymphomas) can be delayed by treating the mice from the time of weaning with metformin or phenformin, or by another AMPK activator, A769662 [79]. Since the 
biguanides and A-769662 activate AMPK by different mechanisms [14], it is unlikely that the delay in tumorigenesis is due to off-target, AMPK-independent effects. In addition, neither class of drug activates any of the ARKs, making it unlikely that their protective effects have anything to do with other kinases downstream of LKB1. One possible mechanism for this effect (Figure 5b) is that activation of AMPK exerts a cytostatic effect on pre-neoplastic lesions through its ability to inhibit cell growth and progress through the cell cycle, and in this way delays the onset of tumorigenesis.

An alternative mechanism whereby biguanides could lead to the suppression of tumor growth derives from the inhibition by these drugs of the mitochondrial respiratory chain (Figure 5c) [14,80], although this action depends, paradoxically, not on the activation of the LKB1-AMPK pathway but on its down-regulation. Because cells with a defective LKB1-AMPK pathway are less able to restore ATP levels in response to metabolic stress [44,81,82], tumor cells in which the pathway has been downregulated may be less able to adapt to mitochondrial inhibition by biguanides, and thus more susceptible to cell death. There is some direct experimental support for this mechanism in the mouse xenograft study of MC38 colon carcinoma cells mentioned earlier [78], in which treatment with metformin reduced the rate of tumor growth in insulin-resistant mice: growth of the xenografts was also slowed by metformin even when the mice were not insulin-resistant, but only if LKB1 had been first knocked down in the tumor cells using RNA interference. In another elegant study involving a mouse model of non-small cell lung cancer, phenformin prolonged survival of the mice when tumors were induced by activation of mutant K-Ras combined with loss of LKB1, but not when the mutant K-Ras was combined with loss of p53 [83]. Phenformin was used in this study because it is a more potent inhibitor of the respiratory chain than metformin [80], and appears to be less dependent on the expression of specific membrane transporters for its cellular uptake [14]. This again is consistent with the proposal that biguanides kill LKB1-deficient tumor cells because they are more sensitive to their ATP-depleting effects than the surrounding normal cells, which would still have a functional AMPK pathway. (Interestingly, cells classed as 'cancer stem cells' appear to be particularly sensitive to metformin, although the molecular mechanism underlying this is unclear $[84,85]$.)

\section{AMPK - tumor suppressor or tumor promoter?}

Since our paper and the others [1-3] published nearly ten years ago suggested a link between AMPK and cancer, the once separate worlds of AMPK and metabolism, and mitogenic signaling in cancer cells have undergone a remarkable fusion. Considerable excitement has also been generated by the realization that inexpensive biguanide drugs with manageable side effects might have new applications in cancer. Pilot 'window-of-opportunity' trials of metformin in breast cancer have already been conducted $[86,87]$, and much more ambitious prospective trials are planned.

However, it is also becoming apparent, as seen in the papers described above, that under different circumstances AMPK can be either a suppressor or a promoter of cancer. In the light of recent evidence, it seems possible that this may depend upon the stage in the development of the tumor. In pre-neoplastic lesions AMPK may act as a tumor suppressor, limiting cell growth and the switch from oxidative metabolism to the Warburg effect, and thus preventing conversion to fullblown tumors: in this case, the pre-neoplastic cells will be under strong selective pressure to down-regulate the LKB1-AMPK pathway, explaining the observed inactivation of LKB1 in a significant proportion of tumors. Paradoxically, however, if a tumor becomes established without losing the function of the LKB1AMPK pathway, AMPK may help to keep the tumor cells alive by protecting them from metabolic stress. There is recent evidence in favor of the latter proposition. In a study of LKB1-deficient lung adenocarcinoma (A549) cells, it was found that re-expression of LKB1 protected the cells against cell death induced by glucose starvation, apparently through inhibition of fatty acid synthesis by AMPK and consequent sparing of NADPH, which could be utilized to provide protection against the oxidative stress induced by glucose deprivation [88]. In another study [89], both AMPK and the AMPK-related kinase NUAK1 (Ark5) were detected in a synthetic lethal RNA interference screen for kinases whose knock-down caused apoptosis of osteosarcoma (U2OS) cells overexpressing c-Myc. This suggests that AMPK and NUAK1 normally help to protect these cells against the stresses caused by the metabolic reprogramming that accompanies c-Myc over-expression.

Thus, the LKB1-AMPK pathway may act as a tumor suppressor through its ability to restrain the growth of pre-neoplastic lesions, but paradoxically may make established tumor cells more resistant to the metabolic stresses induced by biguanides or cytotoxic drugs, or that occurs when growth of the tumor outstrips the capacity of its blood supply to deliver oxygen and nutrients. It thus seems possible that the use of AMPK activators might be harmful in such cases, and there might be a need instead for specific inhibitors of AMPK.

This view is consistent with the recent study of a mouse model of non-small cell lung cancer already discussed above [83], which suggested that biguanides might be an effective method to treat tumors in which the function of the LKB1-AMPK pathway has been lost. In this situation, 
biguanides are acting not as AMPK activators but as cytotoxic drugs that deplete cellular ATP. This study also suggested that phenformin might be more effective than metformin in this regard, because it is more cellpermeable and a more potent inhibitor of the respiratory chain. Although phenformin was withdrawn for treatment of diabetes due to cases of lactic acidosis, this side effect was rare $(<1$ case per 1,000 patient-years) and might be more acceptable in treatment of cancer. Overall, a better understanding of the way in which the varied actions of AMPK interact with the different metabolic requirements of cancer cells is clearly essential to allow the more rational design of clinical trials of metformin and other AMPK-modulating drugs.

\section{Future directions, both upstream of AMPK and downstream of LKB1}

The other major findings that emerged in the immediate aftermath of our 2003 paper were that LKB1 also acted upstream of the AMPK-related kinases or ARKs, and that AMPK could also be activated by the $\mathrm{Ca}^{2+}-\mathrm{CaMKK}$ pathway. Although the functions of the ARKs have been slowly emerging since then, their regulation remains poorly understood. LKB1 appears to be constitutively active, and in the case of AMPK the regulation of Thr172 phosphorylation is brought about by binding of ligands to AMPK, and not to LKB1. In the case of the ARKs, we do not understand how their phosphorylation by LKB1, and hence their activity, is regulated. Much also remains to be learned about the physiological role of AMPK activation by the $\mathrm{Ca}^{2+}-\mathrm{CaMKK}$ pathway. One intriguing question is whether inhibition of cell growth and proliferation by AMPK can be triggered by this pathway in tumor cells that have lost LKB1.

This article is part of the BMC Biology tenth anniversary series. Other articles in this series can be found at http://www.biomedcentral.com/ bmcbiol/series/tenthanniversary.

\section{Acknowledgements}

DGH is currently supported by a Senior Investigator Award (097726) from the Wellcome Trust and a Programme Grant (C37030/A15101) from Cancer Research UK. DRA is supported by the Medical Research Council. DRA and DGH are also supported by the pharmaceutical companies supporting the Division of Signal Transduction Therapy Unit (AstraZeneca, BoehringerIngelheim, GlaxoSmithKline, Merck KgaA, Janssen Pharmaceutica and Pfizer).

\section{Author details}

'Division of Cell Signalling and Immunology, College of Life Sciences, University of Dundee, Dundee, DD1 5EH, Scotland, UK. ${ }^{2}$ MRC Protein Phosphorylation Unit, College of Life Sciences, University of Dundee, Dundee, DD1 5EH, Scotland, UK.

Published: 15 April 2013

\section{References}

1. Hawley SA, Boudeau J, Reid JL, Mustard KJ, Udd L, Makela TP, Alessi DR, Hardie $D G$ : Complexes between the LKB1 tumor suppressor, STRADa/ $\beta$ and $\mathrm{MO} 25 \mathrm{a} / \beta$ are upstream kinases in the AMP-activated protein kinase cascade. J Bio/ 2003, 2:28.
2. Woods A, Johnstone SR, Dickerson K, Leiper FC, Fryer LG, Neumann D, Schlattner U, Wallimann T, Carlson M, Carling D: LKB1 is the upstream kinase in the AMP-activated protein kinase cascade. Curr Biol 2003, 13:2004-2008.

3. Shaw RJ, Kosmatka M, Bardeesy N, Hurley RL, Witters LA, DePinho RA, Cantley LC: The tumor suppressor LKB1 kinase directly activates AMP-activated kinase and regulates apoptosis in response to energy stress. Proc Natl Acad SciUSA 2004, 101:3329-3335.

4. Warburg O, Posener K, Negelein E: Uber den Stoffwechsel der Tumoren. Biochem Z 1924, 152:319-344

5. Vander Heiden MG, Cantley LC, Thompson CB: Understanding the Warburg effect: the metabolic requirements of cell proliferation. Science 2009, 324:1029-1033.

6. Yeh LA, Lee KH, Kim KH: Regulation of rat liver acetyl-CoA carboxylase. Regulation of phosphorylation and inactivation of acetyl-CoA carboxylase by the adenylate energy charge. J Biol Chem 1980, 255:2308-2314.

7. Ingebritsen TS, Lee H, Parker RA, Gibson DM: Reversible modulation of the activities of both liver microsomal hydroxymethylglutaryl Coenzyme A reductase and its inactivating enzyme. Evidence for regulation by phosphorylation-dephosphorylation. Biochem Biophys Res Comm 1978, 81:1268-1277.

8. Carling D, Zammit VA, Hardie DG: A common bicyclic protein kinase cascade inactivates the regulatory enzymes of fatty acid and cholesterol biosynthesis. FEBS Lett 1987, 223:217-222.

9. Hardie DG, Carling D, Sim ATR: The AMP-activated protein kinase - a multisubstrate regulator of lipid metabolism. Trends Biochem Sci 1989, $14: 20-23$

10. Winder WW, Hardie DG: Inactivation of acetyl-CoA carboxylase and activation of AMP-activated protein kinase in muscle during exercise. Am J Physiol 1996, 270:E299-E304.

11. Merrill GM, Kurth E, Hardie DG, Winder WW: AICAR decreases malonyl-CoA and increases fatty acid oxidation in skeletal muscle of the rat. Am J Physiol 1997, 273:E1107-E1112.

12. Winder WW, Hardie DG: The AMP-activated protein kinase, a metabolic master switch: possible roles in type 2 diabetes. Am J Physiol 1999, 277:E1-E10

13. Zhou G, Myers R, Li Y, Chen Y, Shen X, Fenyk-Melody J, Wu M, Ventre J, Doebber T, Fujii N, Musi N, Hirshman MF, Goodyear LJ, Moller DE: Role of AMP-activated protein kinase in mechanism of metformin action. J Clin Invest 2001, 108:1167-1174.

14. Hawley SA, Ross FA, Chevtzoff C, Green KA, Evans A, Fogarty S, Towler MC, Brown LJ, Ogunbayo OA, Evans AM, Hardie DG: Use of cells expressing gamma subunit variants to identify diverse mechanisms of AMPK activation. Cell Metab 2010, 11:554-565.

15. Xiao B, Sanders MJ, Underwood E, Heath R, Mayer FV, Carmena D, Jing C, Walker PA, Eccleston JF, Haire LF, Saiu P, Howell SA, Aasland R, Martin SR, Carling D, Gamblin SJ: Structure of mammalian AMPK and its regulation by ADP. Nature 2011, 472:230-233.

16. Xiao B, Heath R, Saiu P, Leiper FC, Leone P, Jing C, Walker PA, Haire L, Eccleston JF, Davis CT, Martin SR, Carling D, Gamblin SJ: Structural basis for AMP binding to mammalian AMP-activated protein kinase. Nature 2007, 449:496-500

17. Hawley SA, Davison M, Woods A, Davies SP, Beri RK, Carling D, Hardie DG: Characterization of the AMP-activated protein kinase kinase from rat liver, and identification of threonine-172 as the major site at which it phosphorylates and activates AMP-activated protein kinase. J Biol Chem 1996, 271:27879-27887.

18. Woods A, Munday MR, Scott J, Yang X, Carlson M, Carling D: Yeast SNF1 is functionally related to mammalian AMP-activated protein kinase and regulates acetyl-CoA carboxylase in vivo. J Biol Chem 1994, 269:19509-19515.

19. Mitchelhill Kl, Stapleton D, Gao G, House C, Michell B, Katsis F, Witters LA, Kemp BE: Mammalian AMP-activated protein kinase shares structural and functional homology with the catalytic domain of yeast Snf1 protein kinase. J Biol Chem 1994, 269:2361-2364.

20. Nath N, McCartney RR, Schmidt MC: Yeast Pak1 kinase associates with and activates Snf1. Mol Cell Biol 2003, 23:3909-3917.

21. Sutherland CM, Hawley SA, McCartney RR, Leech A, Stark MJ, Schmidt MC, Hardie DG: Elm1p is one of three upstream kinases for the Saccharomyces cerevisiae SNF1 complex. Curr Biol 2003, 13:1299-1305.

22. Hong SP, Leiper FC, Woods A, Carling D, Carlson M: Activation of yeast Snf and mammalian AMP-activated protein kinase by upstream kinases. Proc Natl Acad Sci U S A 2003, 100:8839-8843. 
23. Hemminki A, Markie D, Tomlinson I, Avizienyte E, Roth S, Loukola A, Bignell G, Warren W, Aminoff M, Hoglund P, Jarvinen H, Kristo P, Pelin K, Ridanpaa M, Salovaara R, Toro T, Bodmer W, Olschwang S, Olsen AS, Stratton MR, de la Chapelle A, Aaltonen LA: A serine/threonine kinase gene defective in Peutz-Jeghers syndrome. Nature 1998, 391:184-187

24. Jenne DE, Reimann H, Nezu J, Friedel W, Loff S, Jeschke R, Muller O, BackW, Zimmer M: Peutz-Jeghers syndrome is caused by mutations in a novel serine threonine kinase. Nat Genet 1998, 18:38-43.

25. Baas AF, Boudeau J, Sapkota GP, Smit L, Medema R, Morrice NA, Alessi DR, Clevers HC: Activation of the tumour suppressor kinase LKB1 by the STE20like pseudokinase STRAD. EMBO J 2003, 22:3062-3072.

26. Boudeau J, Baas AF, Deak M, Morrice NA, Kieloch A, Schutkowski M, Prescott AR, Clevers HC, Alessi DR: MO25a/b interact with STRADa/b enhancing their ability to bind, activate and localize LKB1 in the cytoplasm. EMBO J 2003, 22:5102-5114

27. Hawley SA, Selbert MA, Goldstein EG, Edelman AM, Carling D, Hardie DG: 5'-AMP activates the AMP-activated protein kinase cascade, and $\mathrm{Ca}^{2+}$ / calmodulin the calmodulin-dependent protein kinase I cascade, via three independent mechanisms. J Bio/ Chem 1995, 270:27186-27191.

28. Davies SP, Helps NR, Cohen PTW, Hardie DG: 5'-AMP inhibits dephosphorylation, as well as promoting phosphorylation, of the AMPactivated protein kinase. Studies using bacterially expressed human protein phosphatase-2Ca and native bovine protein phosphatase- $2 \mathrm{~A}_{\mathrm{c}}$. FEBS Lett 1995, 377:421-425.

29. Oakhill JS, Steel R, Chen ZP, Scott JW, Ling N, Tam S, Kemp BE: AMPK is a direct adenylate charge-regulated protein kinase. Science 2011, 332:1433-1435.

30. Alessi DR, James SR, Downes CP, Holmes AB, Gaffney PR, Reese CB, Cohen P: Characterization of a 3-phosphoinositide-dependent protein kinase which phosphorylates and activates protein kinase Balpha. Current Biol 1997, 7:261-269.

31. Mora A, Komander D, van Aalten DM, Alessi DR: PDK1, the master regulator of AGC kinase signal transduction. Semin Cell Dev Biol 2004, 15:161-170.

32. Manning G, Whyte DB, Martinez R, Hunter T, Sudarsanam S: The protein kinase complement of the human genome. Science 2002, 298:1912-1934.

33. Lizcano JM, Göransson O, Toth R, Deak M, Morrice NA, Boudeau J, Hawley SA, Udd L, Mäkelä TP, Hardie DG, Alessi DR: LKB1 is a master kinase that activates 13 protein kinases of the AMPK subfamily, including the MARK/ PAR-1 kinases. EMBO J 2004, 23:833-843.

34. Jaleel M, McBride A, Lizcano JM, Deak M, Toth R, Morrice NA, Alessi DR: Identification of the sucrose non-fermenting related kinase SNRK, as a novel LKB1 substrate. FEBS Lett 2005, 579:1417-1423.

35. Al-Hakim AK, Goransson O, Deak M, Toth R, Campbell DG, Morrice NA, Prescott AR, Alessi DR: 14-3-3 cooperates with LKB1 to regulate the activity and localisation of QSK and SIK. J Cell Sci 2005, 118:5561-5573.

36. Hawley SA, Pan DA, Mustard KJ, Ross L, Bain J, Edelman AM, Frenguelli BG, Hardie DG: Calmodulin-dependent protein kinase kinase-beta is an alternative upstream kinase for AMP-activated protein kinase. Cell Metab 2005, 2:9-19.

37. Woods A, Dickerson K, Heath R, Hong SP, Momcilovic M, Johnstone SR, Carlson M, Carling D: Ca2+/calmodulin-dependent protein kinase kinasebeta acts upstream of AMP-activated protein kinase in mammalian cells. Cell Metab 2005, 2:21-33.

38. Hurley RL, Anderson KA, Franzone JM, Kemp BE, Means AR, Witters LA: The $\mathrm{Ca}^{2+} /$ calmoldulin-dependent protein kinase kinases are AMP-activated protein kinase kinases. J Bio/ Chem 2005, 280:29060-29066.

39. Tamas P, Hawley SA, Clarke RG, Mustard KJ, Green K, Hardie DG, Cantrell DA: Regulation of the energy sensor AMP-activated protein kinase by antigen receptor and Ca2+ in T lymphocytes. J Exp Med 2006, 203:1665-1670.

40. Stahmann N, Woods A, Carling D, Heller R: Thrombin activates AMPactivated protein kinase in endothelial cells via a pathway involving $\mathrm{Ca} 2+/$ calmodulin-dependent protein kinase kinase beta. Mol Cell Bio/ 2006, 26:5933-5945.

41. Andersson U, Filipsson K, Abbott CR, Woods A, Smith K, Bloom SR, Carling D, Small CJ: AMP-activated protein kinase plays a role in the control of food intake. J Biol Chem 2004, 279:12005-12008.

42. Yang Y, Atasoy D, Su HH, Sternson SM: Hunger states switch a flip-flop memory circuit via a synaptic AMPK-dependent positive feedback loop. Cell 2011, 146:992-1003.

43. Fogarty S, Hawley SA, Green KA, Saner N, Mustard KJ, Hardie DG: Calmodulindependent protein kinase kinase-beta activates AMPK without forming a stable complex - synergistic effects of Ca2+ and AMP. Biochem J 2010, 426:109-118.

44. Sakamoto K, McCarthy A, Smith D, Green KA, Hardie DG, Ashworth A, Alessi DR: Deficiency of LKB1 in skeletal muscle prevents AMPK activation and glucose uptake during contraction. EMBO J 2005, 24:1810-1820.

45. O'Neill HM, Maarbjerg SJ, Crane JD, Jeppesen J, Jorgensen SB, Schertzer JD, Shyroka O, Kiens B, van Denderen BJ, Tarnopolsky MA, Kemp BE, Richter EA, Steinberg GR: AMP-activated protein kinase (AMPK) \{beta\}1\{beta\}2 muscle null mice reveal an essential role for AMPK in maintaining mitochondrial content and glucose uptake during exercise. Proc Natl Acad Sci U S A 2011, 108:16092-16097.

46. Koo SH, Flechner L, Qi L, Zhang X, Screaton RA, Jeffries S, Hedrick S, Xu W, Boussouar F, Brindle P, Takemori H, Montminy M: The CREB coactivator TORC2 is a key regulator of fasting glucose metabolism. Nature 2005 437:1 109-1114.

47. Kyriakis JM: At the crossroads: AMP-activated kinase and the LKB1 tumor suppressor link cell proliferation to metabolic regulation. J Bio/ 2003, 2:26.

48. Kato K, Ogura T, Kishimoto A, Minegishi Y, Nakajima N, Miyazaki M, Esumi H: Critical roles of AMP-activated protein kinase in constitutive tolerance of cancer cells to nutrient deprivation and tumor formation. Oncogene 2002, 21:6082-6090.

49. Imamura K, Ogura T, Kishimoto A, Kaminishi M, Esumi H: Cell cycle regulation via 553 phosphorylation by a 5 -AMP activated protein kinase activator, 5-aminoimidazole- 4-carboxamide-1-beta-d- ribofuranoside, in a human hepatocellular carcinoma cell line. Biochem Biophys Res Commun 2001, 287:562-567.

50. Faubert B, Boily G, Izreig S, Griss T, Samborska B, Dong Z, Dupuy F, Chambers C, Fuerth BJ, Viollet B, Mamer OA, Avizonis D, Deberardinis RJ, Siegel PM, Jones RG: AMPK is a negative regulator of the Warburg effect and suppresses tumor growth In vivo. Cell Metab 2012, 17:113-124.

51. Jones RG, Plas DR, Kubek S, Buzzai M, Mu J, Xu Y, Birnbaum MJ, Thompson CB: AMP-activated protein kinase induces a p53-dependent metabolic checkpoint. Mol Cell 2005, 18:283-293.

52. Liang J, Shao SH, Xu ZX, Hennessy B, Ding Z, Larrea M, Kondo S, Dumont DJ, Gutterman JU, Walker CL, Slingerland JM, Mills GB: The energy sensing LKB1AMPK pathway regulates $\mathrm{p} 27$ (kip 1) phosphorylation mediating the decision to enter autophagy or apoptosis. Nat Cell Bio/ 2007, 9:218-224.

53. Hardie DG: AMP-activated/SNF1 protein kinases: conserved guardians of cellular energy. Nat Rev Mol Cell Bio/ 2007, 8:774-785.

54. Hardie DG, Ross FA, Hawley SA: AMPK: a nutrient and energy sensor that maintains energy homeostasis. Nat Rev Mol Cell Biol 2012, 13:251-262.

55. Inoki K, Zhu T, Guan KL: TSC2 mediates cellular energy response to contro cell growth and survival. Cell 2003, 115:577-590.

56. Gwinn DM, Shackelford DB, Egan DF, Mihaylova MM, Mery A, Vasquez DS, Turk BE, Shaw RJ: AMPK phosphorylation of raptor mediates a metabolic checkpoint. Mol Cell 2008, 30:214-226.

57. Barnes $\mathrm{K}$, Ingram JC, Porras OH, Barros LF, Hudson ER, Fryer LG, Foufelle F, Carling D, Hardie DG, Baldwin SA: Activation of GLUT1 by metabolic and osmotic stress: potential involvement of AMP-activated protein kinase (AMPK). J Cell Sci 2002, 115:2433-2442.

58. Marsin AS, Bouzin C, Bertrand L, Hue L: The stimulation of glycolysis by hypoxia in activated monocytes is mediated by AMP-activated protein kinase and inducible 6-phosphofructo-2-kinase. J Biol Chem 2002, 277:30778-30783.

59. Marsin AS, Bertrand L, Rider MH, Deprez J, Beauloye C, Vincent MF, Van den Berghe G, Carling D, Hue L: Phosphorylation and activation of heart PFK-2 by AMPK has a role in the stimulation of glycolysis during ischaemia. Current Biol 2000, 10:1247-1255.

60. Canto C, Gerhart-Hines Z, Feige JN, Lagouge M, Noriega L, Milne JC, Elliott PJ, Puigserver $P$, Auwerx J: AMPK regulates energy expenditure by modulating NAD(+) metabolism and SIRT1 activity. Nature 2009, 458:1056-1060.

61. Winder WW, Holmes BF, Rubink DS, Jensen EB, Chen M, Holloszy JO: Activation of AMP-activated protein kinase increases mitochondrial enzymes in skeletal muscle. J Appl Physiol 2000, 88:2219-2226.

62. Thomas GV, Tran C, Mellinghoff IK, Welsbie DS, Chan E, Fueger B, Czernin J, Sawyers CL: Hypoxia-inducible factor determines sensitivity to inhibitors of mTOR in kidney cancer. Nat Med 2006, 12:122-127.

63. Shackelford DB, Vasquez DS, Corbeil J, Wu S, Leblanc M, Wu CL, Vera DR, Shaw RJ: mTOR and HIF-1alpha-mediated tumor metabolism in an LKB1 mouse model of Peutz-Jeghers syndrome. Proc Natl Acad Sci U S A 2009, 106:11137-11142. 
64. Sanchez-Cespedes M, Parrella P, Esteller M, Nomoto S, Trink B, Engles JM, Westra WH, Herman JG, Sidransky D: Inactivation of LKB1/STK11 is a common event in adenocarcinomas of the lung. Cancer Res 2002, 62:3659-3662.

65. Ji H, Ramsey MR, Hayes DN, Fan C, McNamara K, Kozlowski P, Torrice C, Wu MC, Shimamura T, Perera SA, Liang MC, Cai D, Naumov GN, Bao L, Contreras CM, Li D, Chen L, Krishnamurthy J, Koivunen J, Chirieac LR, Padera RF, Bronson RT, Lindeman NI, Christiani DC, Lin X, Shapiro Gl, Janne PA, Johnson BE, Meyerson M, Kwiatkowski DJ, Castrillon DH, Bardeesy N, Sharpless NE, Wong KK: LKB1 modulates lung cancer differentiation and metastasis. Nature 2007, 448:807-810.

66. Wingo SN, Gallardo TD, Akbay EA, Liang MC, Contreras CM, Boren T, Shimamura T, Miller DS, Sharpless NE, Bardeesy N, Kwiatkowski DJ, Schorge JO, Wong KK, Castrillon DH: Somatic LKB1 mutations promote cervical cancer progression. PLOS ONE 2009, 4:e5137.

67. Liu W, Monahan KB, Pfefferle AD, Shimamura T, Sorrentino J, Chan KT, Roadcap DW, Ollila DW, Thomas NE, Castrillon DH, Miller CR, Perou CM, Wong KK, Bear JE, Sharpless NE: LKB1/STK11 inactivation leads to expansion of a prometastatic tumor subpopulation in melanoma. Cancer Cell 2012, 21:751-764.

68. Lee CW, Wong LL, Tse EY, Liu HF, Leong VY, Lee JM, Hardie DG, Ng IO, Ching YP: AMPK promotes $\mathrm{p} 53$ acetylation via phosphorylation and inactivation of SIRT1 in liver cancer cells. Cancer Res 2012, 72:4394-4404.

69. Zheng B, Jeong JH, Asara JM, Yuan YY, Granter SR, Chin L, Cantley LC: Oncogenic B-RAF negatively regulates the tumor suppressor LKB1 to promote melanoma cell proliferation. Mol Cell 2009, 33:237-247.

70. Horman S, Vertommen D, Heath R, Neumann D, Mouton V, Woods A, Schlattner U, Wallimann T, Carling D, Hue L, Rider MH: Insulin antagonizes ischemia-induced Thr172 phosphorylation of AMP-activated protein kinase alpha-subunits in heart via hierarchical phosphorylation of Ser485/491. J Biol Chem 2006, 281:5335-5340.

71. Yuan $\mathrm{TL}$, Cantley LC: PI3K pathway alterations in cancer: variations on a theme. Oncogene 2008, 27:5497-5510.

72. Street A, Macdonald A, Crowder K, Harris M: The hepatitis C virus NS5A protein activates a phosphoinositide 3-kinase-dependent survival signaling cascade. J Biol Chem 2004, 279:12232-12241.

73. Mankouri J, Tedbury PR, Gretton S, Hughes ME, Griffin SD, Dallas ML, Green KA, Hardie DG, Peers C, Harris M: Enhanced hepatitis C virus genome replication and lipid accumulation mediated by inhibition of AMPactivated protein kinase. Proc Natl Acad Sci U S A 2010, 107:11549-11554.

74. Evans JM, Donnelly LA, Emslie-Smith AM, Alessi DR, Morris AD: Metformin and reduced risk of cancer in diabetic patients. BM/2005, 330:1304-1305.

75. Decensi A, Puntoni M, Goodwin P, Cazzaniga M, Gennari A, Bonanni B, Gandini S: Metformin and cancer risk in diabetic patients: a systematic review and meta-analysis. Cancer Prev Res (Phila) 2010, 3:1451-1461.

76. Suissa S, Azoulay L: Metformin and the risk of cancer: time-related biases in observational studies. Diabetes Care 2012, 35:2665-2673.

77. Pollak M: The insulin and insulin-like growth factor receptor family in neoplasia: an update. Nat Rev Cancer 2012, 12:159-169.
78. Algire C, Amrein L, Bazile M, David S, Zakikhani M, Pollak M: Diet and tumor LKB1 expression interact to determine sensitivity to anti-neoplastic effects of metformin in vivo. Oncogene 2011, 30:1174-1182.

79. Huang X, Wullschleger S, Shpiro N, McGuire VA, Sakamoto K, Woods YL, McBurnie W, Fleming S, Alessi DR: Important role of the LKB1-AMPK pathway in suppressing tumorigenesis in PTEN-deficient mice. Biochem J 2008, 412:211-221.

80. Owen MR, Doran E, Halestrap AP: Evidence that metformin exerts its antidiabetic effects through inhibition of complex 1 of the mitochondrial respiratory chain. Biochem J 2000, 348:607-614.

81. Russell RR, 3rd, Li J, Coven DL, Pypaert M, Zechner C, Palmeri M, Giordano FJ, Mu J, Birnbaum MJ, Young LH: AMP-activated protein kinase mediates ischemic glucose uptake and prevents postischemic cardiac dysfunction, apoptosis, and injury. J Clin Invest 2004, 114:495-503.

82. Foretz M, Hebrard S, Leclerc J, Zarrinpashneh E, Soty M, Mithieux G, Sakamoto $\mathrm{K}$, Andreelli F, Viollet B: Metformin inhibits hepatic gluconeogenesis in mice independently of the LKB1/AMPK pathway via a decrease in hepatic energy state. J Clin Invest 2010, 120:2355-2369.

83. Shackelford DB, Abt E, Gerken L, Vasquez DS, Seki A, Leblanc M, Wei L, Fishbein MC, Czernin J, Mischel PS, Shaw RJ: LKB1 inactivation dictates therapeutic response of non-small cell lung cancer to the metabolism drug phenformin. Cancer Cell 2013, 23:143-158.

84. Hirsch HA, Iliopoulos D, Tsichlis PN, Struhl K: Metformin selectively targets cancer stem cells, and acts together with chemotherapy to block tumor growth and prolong remission. Cancer Res 2009, 69:7507-7511.

85. Song CW, Lee H, Dings RP, Williams B, Powers J, Santos TD, Choi BH, Park HJ: Metformin kills and radiosensitizes cancer cells and preferentially kills cancer stem cells. Sci Rep 2012, 2:362.

86. Niraula S, Dowling RJ, Ennis M, Chang MC, Done SJ, Hood N, Escallon J, Leong WL, McCready DR, Reedijk M, Stambolic V, Goodwin PJ: Metformin in early breast cancer: a prospective window of opportunity neoadjuvant study. Breast Cancer Res Treat 2012, 135:821-830.

87. Hadad S, Iwamoto T, Jordan L, Purdie C, Bray S, Baker L, Jellema G, Deharo S, Hardie DG, Pusztai L, Moulder-Thompson S, Dewar JA, Thompson AM: Evidence for biological effects of metformin in operable breast cancer: a pre-operative, window-of-opportunity, randomized trial. Breast Cancer Res Treat 2011, 128:783-794.

88. Jeon SM, Chandel NS, Hay N: AMPK regulates NADPH homeostasis to promote tumour cell survival during energy stress. Nature 2012, 485:661-665.

89. Liu L, Ulbrich J, Muller J, Wustefeld T, Aeberhard L, Kress TR, Muthalagu N, Rycak L, Rudalska R, Moll R, Kempa S, Zender L, Eilers M, Murphy DJ: Deregulated MYC expression induces dependence upon AMPK-related kinase 5. Nature 2012, 483:608-612.

doi:10.1186/1741-7007-11-36

Cite this article as: Hardie DG, Alessi DR: LKB1 and AMPK and the cancermetabolism link - ten years after. BMC Biology 2013, 11:36. 